\title{
REPRESENTACIÓN DE LA POESÍA DE ANDRÉS SÁNCHEZ ROBAYNA EN SUS ÚLTIMAS ANTOLOGÍAS (2012 Y 2016)
}

\author{
José Francisco RUIZ CASANOVA \\ Universitat Pompeu Fabra
}

$\mathrm{H}$

ace diez años, al escribir mi estudio sobre las antologías poéticas, ensayé en sus páginas una tipología de las mismas en función de varios parámetros: el primero de ellos enfrentaba las antologías panorámicas a las programáticas, considerando, además, que estas últimas o bien daban cuenta de la actualidad, o bien servían para marcar territorios estéticos. Por su parte, las antologías panorámicas alcanzaban en aquella clasificación hasta diez subcategorías, siendo ahora las que nos interesan las antologías de un solo autor, bien editadas por un antólogo, bien con formato de autoantología.

Para la historia de la poesía de un autor, para su trascendencia más allá de los cortos límites temporales de su contemporaneidad, las antologías han ejercido siempre una doble función: son, por una parte, testimonio, elección y representación de lo mejor o lo más significativo de su obra o de una parte de ésta; por otra, son un escalón más en el ascenso a esa cumbre de la notoriedad histórica e historiográfica que usualmente comienza con la publicación de unos pocos poemas en alguna revista, la edición de algunas plaquettes y la inclusión en antologías poéticas de época o de grupo. Mucho más adelante, cuando la obra está granada y asentada -si es que ello se produce, cuestión ésta en la que mucho tiene que ver la voluntad del autor- suelen llegar las antologías panorámicas del total de su obra (hasta el momento editorial de la selección) o los proyectos de obras completas.

Las antologías de autor requieren ciertas condiciones materiales y personales. Por una parte, el antólogo que, caso de no ser el propio poeta erigido en autoantólogo, no sólo debe conocer bien la obra del poeta que va a presentar en selección sino que debe reunir rasgos propios de su etopeya como crítico y como antólogo: conocer la obra -como se ha dicho-, poseer un discurso crítico y una poética propia de lectura para dicho poeta, gozar de la confianza del autor y de autonomía total a la hora de realizar su trabajo. Como veremos, muchas de estas condiciones se cumplen parcialmente cuando el antólogo afronta su trabajo, sobre todo si, como suele ser, se trata de seleccionar la obra de un poeta vivo. Y el cumplimiento, o no, de tales premisas tanto tiene que ver con las intervenciones humanas -varias- que sobre el libro operan como, también, con el hecho de que la antología, como producto editorial que es, se ajusta asimismo a condicionantes de producción como son las 
características de la editorial que la imprime, de la colección en que se inserta o la tirada y distribución que el libro tendrá; todo ello por no hablar de la estructura formal del libro: número de páginas, criterio cronológico para la selección (desde la selección de poemas de toda la obra hasta la selección de poemas de una parte concreta de la obra), acompañamiento de estudio preliminar o no, e incluso anotación crítica -o no- de los poemas.

De modo que en aquella escala de ascenso que la posteridad traza para el poeta, a los pasos previos antes mencionados habría que sumar ahora, y antes de proyecto alguno de obras completas, diversas antologías de autor. A mi parecer, este estadio del trabajo literario que labra la presencia histórica de una escritura poética debe contemplar no más de tres antologías: una antología panorámica lo más extensa posible, una antología con anotación crítica y una autoantología. Y debe advertirse aquí que el orden cronológico en que estas tres antologías se den no es cuestión sin importancia. Por ejemplo, si pensamos en uno de los poetas que de manera más sistemática, casi obsesiva, construyó su posteridad, Juan Ramón Jiménez, no resultaría difícil en absoluto comprobar cómo sus tres autoantologías (la de 1917, la de 1922 y la de 1957, aun cuando de la conclusión de ésta se encargase Eugenio Florit) han determinado en grado máximo cómo y cuándo se han realizado las selecciones posteriores a la muerte del poeta. Como contraejemplo de esto, como de tantas otras cosas, podríamos traer aquí las operaciones de reunión de libros de poemas, a modo de obras completas provisionales, llevadas a cabo por algunos poetas de la generación del 27 como Jorge Guillén desde 1928, o Luis Cernuda desde 1936.

Pero vuelvo a lo ya referido. Si damos por buena la regla de que un poeta, con gran parte o casi toda su obra ya escrita, precisa de tres antologías de autor para ser representado, y que éstas deben ser una antología panorámica, una antología con anotación crítica y una autoantología, el primer síntoma de la urgencia - o de la necesidad de control sobre su obra-que ejerce el autor lo tendremos en la secuencia cronológica que tales selecciones ocupen. La peor de las opciones es la juanramoniana, pues obvio es que la autoría del poeta como antólogo propio descalifica al antólogo externo, sobre todo para aquellos que crean que el mejor lector de una obra poética es su propio autor. En mi opinión, la secuencia ideal -dejando ahora aparte la tentación de intervención del poeta en las antologías que él no construye- sería aquélla que se inicia con una antología panorámica, sigue con una antología crítica y, finalmente, es el poeta quien realiza su propia selección de textos. De entrada, y salvo aquellos casos, frecuentes no obstante, en los que el poeta ejerce un control férreo sobre la selección que va a imprimirse -y que firma otra persona-, el mismo orden cronológico de publicación de los libros ya nos dice algo a los historiadores de la literatura.

Se me ha solicitado aquí, como autor de un ensayo sobre las antologías y como antólogo que he sido de la poesía de Andrés Sánchez Robayna, que trate de la representación selectiva de su lírica en tales libros. De las tres antologías publicadas entre 2006 y 2016 trataré aquí de dos de ellas, pues la tercera (Ideas de existencia. Antología poética 1970-2002, ed. de Jordi Doce, México, Aldus, 2006) escapa de mi objetivo por una razón principal: haber sido editada en México y tener, por lo tanto, un campo de aplicación cultural y unos objetivos de difusión distintos, aun cuando el libro se 
distribuyera en España. Las dos antologías sobre las que trataré son: El espejo de tinta (Antología 1970-2010), ed. de José Francisco Ruiz Casanova, Madrid, Cátedra, 2012; y Al cúmulo de octubre (Antología poética: 1970-2015), Madrid, Visor, 2016. Mi antología (una selección panorámica con notas críticas, estudio preliminar y editada en una colección de textos clásicos y modernos de la literatura española) ha quedado enmarcada, según capricho cronológico, por un volumen que recogía la obra poética completa del autor hasta 2002 (En el cuerpo del mundo. Obra poética. 1970-2002, Barcelona, Galaxia Gutenberg-Círculo de Lectores, 2004) y la autoantología editada en 2016, de modo que es mi libro la única antología con antólogo externo que editada en España tiene actualmente la poesía de Andrés Sánchez Robayna.

Podría hacer, ahora y a continuación, unas pesadas y aburridas tablas comparativas de poemas y libros seleccionados en cada una de las antologías; pero creo que tal primario ejercicio comparativo puede realizarlo cualquier lector a simple golpe de vista sobre los índices de los libros. Por lo tanto, creo de mayor interés realizar un cierto análisis, o despertar algunas reflexiones, sobre la curiosa y singular situación en la que la cronología antológica de Sánchez Robayna ha situado mi antología, El espejo de tinta (Antología 1970-2010) y cómo o hasta qué punto mi lectura selectiva de su obra -lectura que en el curso de realización de la antología fue, en todo momento, cotejada con el autor- se corresponde o difiere de la autolectura que el poeta hace, cuatro años después, de prácticamente la misma totalidad de poemas, si excluimos una breve sección que bajo el título «Nuevos poemas (2011-2015)» incluye su autoantología.

El espejo de tinta se formó como antología panorámica de toda la trayectoria poética, hasta ese momento (2010), de su autor. De modo que fueron premisas mías como antólogo representar todos y cada uno de los libros y equilibrar el peso de la representación de cada uno de ellos en función de varios parámetros: primero, su representatividad o importancia dentro de la etapa a la que correspondía el libro, punto éste para el cual conté con las propias apreciaciones y referencias hemerográficas y bibliográficas (entrevistas, artículos, reseñas, críticas, estudios) que de tales libros se habían ido haciendo a lo largo del tiempo; segundo, un criterio de ecuanimidad entre la representación de cada libro y la extensión o cantidad de poemas contenidos en él; tercero, una incidencia en la que fue mi lectura crítica de la poesía de Sánchez Robayna (desarrollada en el estudio preliminar, y que atendía, como tesis principal, a la idea de que podían distinguirse en su obra tres etapas); cuarto, la labranza de una suerte de referencias internas, ecos e hilos de coherencia que llevasen al lector de unos poemas a otros, de unos libros a otros; y, por último, una representación generosa -la más amplia en número de poemas- de su última obra, La sombra y la apariencia, y esto por dos razones que no otras eran que éstas: la proximidad temporal entre este libro y mi antología, así como el hecho de que mi estudio defendiera -como he dicho- una labor poética de Sánchez Robayna diferenciada en tres etapas, siendo la última la que acababa de iniciarse con el libro citado y que, de momento, desconocemos cuál será su desarrollo posterior como etapa.

Llevo diciendo y escribiendo sobre la «poética de la antología» al menos desde 1998; y desde entonces he repetido que una antología es un libro, un libro estructurado, y que, como tal, pueden 
exigírsele «la misma coherencia que exigimos al desarrollo argumental de una novela, la distribución de secuencias de un libro de poemas o la configuración de ideas en un ensayo» (2016: 67). Recordaré ahora, pues, lo que trataba con más profundidad en mi ensayo de 2007:

La coherencia del texto antológico no deriva, como es deducible, de supuestos grados de objetividad -a veces invocados por los antólogos- ni por premisas de carácter enciclopédico que, todavía hoy, creen posible hacer de la antología libro de arena. La coherencia de una antología viene determinada, cuando se da o puede darse, por una intersección de múltiples vías en un solo punto: desde las prioridades y criterios establecidos por el antólogo de buen principio (o en el transcurso de sus labores) hasta el conocimiento de la tradición literaria sobre la que trabaja; desde la concepción unitaria del libro y la delimitada incidencia de éste en los márgenes de la historia literaria hasta la muestra (y propuesta) de la continuidad canónica o, antes que ella, historiográfica. Pero la coherencia del libro llamado antología no está en relación directa con las cuestiones relativas a la historia, sin más, sino que reunir una antología implica presentar un modelo político, pues las opciones estéticas ( $\mathrm{y}$ dejemos ahora a un lado los domésticos rifirrafes que coloquialmente denominamos "de política literaria") se corresponden con tales modelos (2007: 189).

Cuando, como en este caso, se confrontan dos lecturas de una misma obra, dos lecturas separadas unos cinco años en el tiempo, realizadas por dos personas distintas (un antólogo y el autor), presentadas con formatos antológicos diferentes (la primera, una antología con notas críticas; la segunda, una autoantología), y a esto se suma que el libro precedente (aun cuando no haya sido firmado por el poeta) ejerce una cierta presión canónica sobre el que le sigue (que en este caso sî firma el poeta, como autor y como autoantólogo), es más que lógico que las diferencias salten a la vista. De haber sido yo quien realizase esta segunda antología, aun siendo antología sin notas críticas, de diferente formato y dirección editorial y comercial, probablemente mi selección no hubiera sido la misma que la que fue en su día para una editorial cuyo catálogo sobrepasa las setecientas ediciones de escritores clásicos y modernos en lengua española: probablemente una ocasión como ésta tarde en repetirse, o no se repita; en cambio, una antología destinada a una colección de poesía no debe sentir la presión de ser, quizá, oportunidad que no se repita. Mas no sólo estas consideraciones que atañen al mercado literario, la difusión y la ubicación de un autor en el parnaso de clásicos y modernos, sino también otras influirían en mi nueva selección: la más poderosa es que, como lector y como antólogo, no soy el mismo lector ni el mismo antólogo que cuando compuse, en 2010-2011, El espejo de tinta.

No obstante -y ya dije antes que no es mi intención comparar los índices ni las selecciones al detalle-, las diferencias entre el antólogo y el autor como autoantólogo se cifran básicamente en tres rasgos que suelen ser bastante comunes: en primer lugar, un buen antólogo debe tener en cuenta todas las consideraciones, y muchas más, que he hecho, esto es, ha de tener una poética de la antología, y no una cualquiera o una poética-comodín sino una poética ajustada a la obra que va a seleccionar; en segundo lugar, y aun cuando el gusto (ese término que me he resistido a escribir hasta ahora) marque predilecciones por poemas o, peor, por libros enteros dentro de la obra, el antólogo debe ser lo suficientemente ecuánime y generoso como para permitir que sus lectores puedan -ellos sí- determinar sus gustos a partir de la selección que están leyendo; y, por último, un antólogo -y en esto suele diferenciarse casi siempre del autor en el rol de autoantólogo- no siempre tiene por qué considerar que es mejor representar con mayor cantidad de poemas la parte final de la obra de un 
poeta que sus inicios, sus vacilaciones o sus transiciones entre unas etapas y otras de su escritura, y éste suele ser un punto de fricción muy generalizado, pues los poetas siempre prefieren que en sus representaciones estén más visibles aquellos libros suyos más queridos (a veces, sólo uno) o el último libro publicado.

Incidiré algo más aun en estas cuestiones. La poética de la antología que alza un antólogo depende, no obstante, de circunstancias varias: la condición -filológica o no- del propio antólogo y, por ende, la condición filológica o no del libro que construye; la posteridad del libro mismo (difieren aquí en su vida los libros en colecciones anotadas de los libros en colecciones de carácter más efímero o comercial); así como todo lo que se deriva del acto de antologar como acto de lectura crítica, filológica e historicista.

No cabe duda, en este sentido, de que una antología que se enmarque en una colección de textos clásicos o modernos anotados, como era la que en su día hice, debe prestar atención no sólo a la inmediatez, al presente del autor o a los gustos del momento en que se realiza sino, también y quizá en mayor medida, a la proyección del libro en la historia de la literatura, a la proyección del autor en la misma y, por qué no, a la proyección de una experiencia de lectura que sea capaz de sobrepasar la frontera de su presente. Al tratarse de una selección, obviamente la falibilidad del procedimiento es de alto rango; aun y con todo, el antólogo tiene el deber -y el derecho- de trazar algo así como un mapa de la posteridad del poeta y de su obra: el tiempo, con sus lectores, muchos de los cuales ni siquiera son contemporáneos del libro, determinará aciertos y errores.

Por decirlo a las claras: aun cuando las antologías sean materia preferida de la tópica de una crítica que de forma coral repite los mismos estigmas y señala las mismas cuestiones, una antología panorámica no sólo debe convivir con la crítica que le es contemporánea sino con la crítica y los lectores del futuro, lo cual no convierte el acto antológico en una suerte de ciencia adivinatoria pero sí -todavía más- en un procedimiento literario y filológico de alto riesgo y de mucha trascendencia histórica. Y es ahí donde el proceso poético de una antología formada por un antólogo, el proceso poético en marcha de un autor vivo que sigue escribiendo y su proceso como autoantólogo pueden diferir y, de hecho, casi siempre difieren. Un poeta que sigue escribiendo desea que sus obras últimas sean apreciadas, contempladas en la totalidad de su lírica, que no se le recuerde siempre por los mismos poemas ni por los mismos libros: su poesía está -según el autor-en otro lugar, aunque éste sea el mismo, y desea abrir por lo tanto ese nuevo espacio al lector de su autoantología.

No se trata de reivindicar aquí la figura del antólogo como sancionador de la obra lírica de un poeta ni de la crítica como el factor canonizador de textos y autores. Nunca he creído que tales funciones, de darse, correspondan a las diversas autorías del texto, sean éstas la del autor legítimo, la del antólogo o la del crítico. He repetido en varias ocasiones que las tan traídas y llevadas cuestiones canónicas no emanan de la crítica contemporánea, ni de los propios autores ni -menos aun- de los antólogos. El Canon es una idea de futuro y, como tal, no nos pertenece ni podemos determinarla, por más esfuerzos que en hacerlo pongamos. 
Una antología debe ser -Sánchez Robayna lo ha dicho en alguna ocasión- como un mapa trazado para que el lector pueda apreciar los límites de una escritura: una antología es una muestra que no sólo representa la totalidad de una escritura sino que, sin la pretensión de suplantar dicha totalidad, hace valer un argumento de lectura y tiene como objetivo fomentar otras lecturas. La antología no es la obra, como tampoco lo es la autoantología. Con la necesaria convivencia de antologías parciales, antologías temporalmente limitadas, antologías panorámicas y autoantologías, incluso antologías colectivas, se ofrece -en los casos en que esto ocurre, que no son todos- una malla de lecturas en la que están comprendidos los elementos fundamentales de la escritura y de la lectura, que no otros son que pasado y presente. Ninguna antología se conjuga en futuro, aunque todas aspiren a dicho tiempo, como libros y como lecturas de una obra.

En la vida como escritor de un poeta se dan, con regularidad, diversos tiempos antológicos: las primeras antologías son una muestra de una etapa, de un conjunto de primeros libros o sanciones del pasado; tras éstas se dan a menudo las selecciones en antologías colectivas (de grupo o de época), a veces antes incluso de las propias antologías de primeras obras, y en ellas están presentes aquellas representaciones (aquellos poemas) que perseguirán al autor durante el resto de su vida antológica; después, avanzada la obra, las antologías de autor devienen antologías temporales que resumen o presentan décadas enteras de producción poética; tales antologías suelen acompañarse de autoantologías y, en los casos en los que la fortuna acompaña, de antologías destinadas a diversos niveles escolares o universitarios, textos anotados y acorazados con un estudio preliminar. A veces, también, se dan antologías de recuperación, en las que viene a practicarse una suerte de arqueología de la escritura primera, remota u olvidada del autor.

El proceso, como podemos imaginar, termina en algunos casos con la edición de la poesía completa, aun cuando no sea éste el único derrotero que la historia o los autores han elegido para sus obras. Por ejemplo, el caso de Juan Ramón Jiménez y sus tres antologías (autoantologías) llamadas Primera, Segunda y Tercera no deja de resultar interesante desde un punto de vista filológico, historicista o simplemente poético: ante la tentación de reunir todo, incluso aquello que, explicándote como poeta, como poeta prefieres no recordar, ante la pulsión de la totalidad, el ejercicio práctico de la selección, o de la autoselección.

Las antologías, en definitiva (también la que de la poesía de Sánchez Robayna realicé, también su autoantología), son obras que pretenden reunir el pasado, imponerse en el presente y determinar el futuro: nada más humano ni nada más utópico que cumplir estas tres premisas. Por una parte reúnen dichos libros obras que alumbraron la lectura de los lectores que ya no somos o de los lectores que, simple y llanamente, ya no existen; por otro, actualizan una imagen poética de la totalidad ante nuestro presente; por último, aspiran a dirigirse a unos lectores que ni conocemos ni con quienes podremos dialogar.

He aquí la grandeza -y la tragedia- del acto antológico en sí y de cualquier aspiración a la posteridad que, sea dicho además, en nada es distinta de la tragedia dialéctica del artista y el tiempo, del hombre y el tiempo. 
138 Tropelías. Revista de Teoría de la Literatura y Literatura Comparada, 29 (2018)

José Francisco Ruiz Casanova

\section{Bibliografía}

Ruiz Casanova, J. F., (1998): «Introducción», en Antología Cátedra de Poesía de las Letras Hispánicas. Madrid, Cátedra, 12ª ed., corregida y aumentada, 2016. (2007): Anthologos: Poética de la antología poética. Madrid, Cátedra.

SÁNCHEZ RoBAynA, A. (2004): En el cuerpo del mundo. Obra poética 1970-2002. Barcelona, Galaxia Gutenberg-Círculo de Lectores.

(2006): Ideas de existencia. Antología poética 1970-2002, ed. de J. DocE. México, Aldus. (2012): El espejo de tinta (Antología 1970-2010), ed. de J. F. RuIz Casanova. Madrid, Cátedra.

(2016): Al cúmulo de octubre (Antología poética: 1970-2015). Madrid, Visor. 